\title{
Why do patients follow physicians' advice? The influence of patients' regulatory focus on adherence: an empirical study in China
}

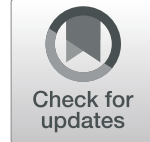

\author{
Runtong Zhang, Xinyi Lu, Wen Wu* and Xiaopu Shang*
}

\begin{abstract}
Background: In general, medical regimens and treatments are more likely to be effective if patients follow their physicians' advice. However, limited studies have focused on the relationship between regulatory focus and patient adherence. This study explores the antecedents of patient adherence employing regulatory focus theory.

Methods: This study established a research model consisting of two independent variables, two mediators, one dependent variable, two moderators, three control variables, and six hypotheses. An online survey involving 336 valid responses was conducted to collect data in China. We used structural equation modelling and confirmatory factor analysis to test the hypotheses and to develop the research model.

Results: The reliability and validity of the measures were accepted. In terms of control variables, age had a positive effect on conservative treatment-related health information seeking behaviour, and patients with different resident statuses held different attitudes towards seeking conservative treatment-related health information. However, educational level did not have any effect on the variables of the research model. The hypothesis testing results corroborate that promotion focus had a positive impact on patients' emerging treatment-related health information seeking behaviour; prevention focus had a positive impact on patients' conservative treatment-related health information seeking behaviour, which had a positive impact on patient adherence. In addition, media campaigns had a positive impact on the relationship between promotion focus and emerging treatment-related health information seeking behaviour, and website reputation had a positive impact on the relationship between prevention focus and conservative treatment-related health information seeking behaviour.

Conclusions: Individuals can be encouraged to seek health information and share health-related knowledge through mass media, such as the Internet, when the quality of information, especially information from online sources, is guaranteed. In addition, physicians need to improve their professionalism and expand their knowledge of conservative healthcare. As a further application of our work, an Internet information recommendation system can be designed to recommend different types of health information for users according to their regulatory focus.
\end{abstract}

Keywords: Regulatory focus, Patient adherence, Physician-patient relationship, Health information seeking, Structural equation modelling

\footnotetext{
* Correspondence: wuwen@bjtu.edu.cn; sxp@bjtu.edu.cn

School of Economics and Management, Beijing Jiaotong University,

Shangyuancun 3, Haidian District, Beijing 100044, China
}

(c) The Author(s). 2019 Open Access This article is distributed under the terms of the Creative Commons Attribution 4.0 International License (http://creativecommons.org/licenses/by/4.0/), which permits unrestricted use, distribution, and reproduction in any medium, provided you give appropriate credit to the original author(s) and the source, provide a link to the Creative Commons license, and indicate if changes were made. The Creative Commons Public Domain Dedication waiver (http://creativecommons.org/publicdomain/zero/1.0/) applies to the data made available in this article, unless otherwise stated. 


\section{Background}

The physician-patient relationship has a significant effect on diagnoses and treatments [1]. In general, medical regimens and treatments are more likely to be effective if patients follow physicians' advice [2], and the quality of the physician-patient relationship plays an important role in improving patient adherence [3]. Adherence (or compliance) is defined as "the extent to which a person's behaviour (in terms of taking medications, following diets, or executing lifestyle changes) coincides with medical or health advice" [4]. Healthcare providers prefer to use "adherence" because "compliance" tends to describe the degree to which patients passively follow physicians' orders and treatments that are formulated by physicians themselves without consulting with patients [5]. Patients with considerably high adherence are likely to become healthier than those with poor adherence [6], and nonadherence may result in several serious financial, social, familial, individual, and psychological problems [7], such as low income due to an inability to work, high medical costs, and even health deterioration [2]. With the increasing proportion of chronic diseases $[8,9]$, patient self-management has become critical in treatments [10]. Thus, patient adherence is particularly important for health and rehabilitation.

Previous studies have suggested that patient adherence should be regarded as a dynamic parameter. In this view, nonadherence to physicians' instructions and treatments may be involuntary. That is, patients may be distracted and forgetful because of certain factors in the treatment process [11]. While involuntary nonadherence may be related to individual characteristics, the rational decision-making process is reflected by voluntary nonadherence.

Some studies have focused on patient adherence and its corresponding influencing factors and consequences. These studies discuss four main aspects: (1) the relationships between patient adherence and various diseases [12-14]; (2) the improvement and optimization of patient adherence $[15,16]$; (3) the factors influencing patient adherence [17-19]; and (4) medicine adherence $[20,21]$. However, related previous studies that explored the relationship between regulatory focus and patient adherence are limited. Thus, the present study investigates the antecedents of patient adherence by employing regulatory focus theory.

Before Crowe and Higgins [22] proposed regulatory focus theory, the pleasure principle had been used as the basic motivational assumption across all fields of psychology to understand individual motivation. The pleasure principle was replaced by regulatory focus theory, which is based on self-discrepancy theory [23] and involves two types of regulatory focus, promotion focus and prevention focus, which are characterized by approach and avoidance motivations, respectively. Promotion focus is concerned with advancement, growth, and accomplishment, and it has a strategic inclination towards achieving progress and approaching the desired end-state. Approach motivation aims to achieve the ideals and aspirations of individuals. It focuses on personal development and self-realization and expects positive results. By contrast, prevention focus is concerned with security, safety, and responsibility, and it has a strategic inclination towards being prudent and precautionary to avoid mismatches with the desired end-state [22]. Avoidance motivation aims to avoid failures and mistakes, to fulfil the responsibilities and obligations of individuals, and to meet the expectations of others without negative results [24].

Apart from physicians, patients also obtain health information from friends, news, books, the Internet and other sources [2]. The health information acquired by patients from daily life may exert both positive and negative effects on the physician-patient relationship. Positive effects are generated when the obtained health information strengthens the confidence of patients in their physicians, encourages patients to make suitable choices and decisions, improves their understanding of their health status, and enhances the physician-patient relationship [25, 26]. However, some patients seek health information because they are dissatisfied or discontented with their physicians. In addition, some physicians believe that their patients cannot assess the reliability of health information, and a minority of physicians may object to their patients seeking other information because they feel challenged, resulting in physician hostility, low healthcare quality, anxiety, and frustration among patients [26, 27]. A previous survey [27] indicated that physicians generally admitted that health information can significantly help improve patients' health; however, $40 \%$ of physicians worried that such health information might adversely affect the physician-patient relationship.

Information behaviour refers to human behaviour that is related to information resources and information channels, including active or passive information seeking behaviour, information utilization behaviour, face-to-face communication behaviour, and passive information receiving behaviour. Information seeking behaviour includes, but is not limited to, two main types of information behaviours: information retrieval and information browsing. Wilson [28] defined information seeking behaviour as a purposeful activity to seek information to satisfy a certain target requirement. Its objective is to meet the information needs of patients and to reduce the information asymmetry between physicians and patients [29]. Patients obtain health information through information seeking behaviour and feel a significant increase in their level of knowledge by reading information [2]. However, Laugesen et al. 
[2] argued that patients sometimes realize that they access only basic information that physicians have already known when they interact with physicians; hence, the perceived information asymmetry still exists. Therefore, a change in patients' perceived information asymmetry is related to the nature of the health information obtained through information seeking behaviour.

This study explores how regulatory focus affects patient adherence through the mediation of information seeking behaviour. Considering that information seeking behaviour is ultimately influenced by different individual characteristics, we assume that patients with different regulatory focuses exhibit different health information seeking behaviours. This difference may produce various information gaps between physicians and patients, thereby affecting patient adherence [2].

\section{Research model and hypotheses}

Regulatory focus theory suggests that individuals with different regulatory focuses constantly perform differently. Specifically, individuals in a promotion focus state are willing to obtain emerging treatment-related information, whereas individuals in a prevention focus state are "conservative" and often make repetitive choices or follow routines to avoid risks. The uncertainty of technical effectiveness makes individuals with a prevention focus hesitant to adopt emerging technology, prompting them to follow previous behaviour rather than innovate [30]. Therefore, we derive the following hypotheses:

H1: Promotion focus has a positive impact on patients' emerging treatment-related health information seeking behaviour.

H2: Prevention focus has a positive impact on the patients' conservative treatment-related health information seeking behaviour.

Patients with a promotion focus are more likely to seek emerging treatment-related health information; their physicians may lack such information because of its "emerging" nature. Through information seeking behaviour, patients may gain much health information. Thus, their perceived information asymmetry may be reduced. By contrast, patients with a prevention focus often obtain conservative treatment-related health information that is already known by physicians. This situation further convinces patients that physicians grasp more information than they do. As a result, patients believe that their physicians have professional knowledge and eventually perceive the increase in information asymmetry. The greater the amount of effective information that patients acquire is, the greater the extent to which they trust in their physicians during the interaction. Laugesen et al. [2] proposed that the greater the information asymmetry, the better the patient adherence. This situation leads to the following hypotheses:

H3: The emerging treatment-related health information seeking behaviour of patients with a promotion focus has a negative impact on their adherence.

H4: The conservative treatment-related health information seeking behaviour of patients with a prevention focus has a positive impact on their adherence.

Mass media, which include television, newspapers, and the Internet, have become an important source of information related to healthy lifestyles. Mass media exert a significant effect on spreading and seeking health information [31], and they play an important role in early diagnoses and disease management [32]. In consideration of the decrease in the credibility of media campaigns [33, 34], patients with a prevention focus are less likely to use mass media than those with a promotion focus. Emerging treatment-related health information is mainly disseminated to the public through mass media. Thus, media campaigns may encourage patients with a promotion focus to seek emerging treatment-related health information. The above discussion leads us to propose the following hypothesis:

H5: If the level of media campaigns increases, then the relationship between promotion focus and emerging treatment-related health information seeking behaviour will be strengthened.

As a main source of health information, the Internet provides a quick and convenient way for individuals to seek health information. Patients with a prevention focus tend to obtain conservative treatment-related health information after much deliberation, for example, by comparing the same information from different websites. Website reputation is produced and diffused online. From the perspective of users, websites with a high reputation are more likely to have high credibility, and reputation is critical in constructing trust between websites and users [35]. Therefore, patients with a prevention focus are more likely to seek conservative treatment-related health information on websites with a high level of reputation. Consequently, we suggest the following hypothesis:

H6: If the level of website reputation increases, then the relationship between prevention focus and conservative treatment-related health information seeking behaviour will be strengthened.

Our research model (see Fig. 1) is established by summarizing the above hypotheses, with promotion focus 


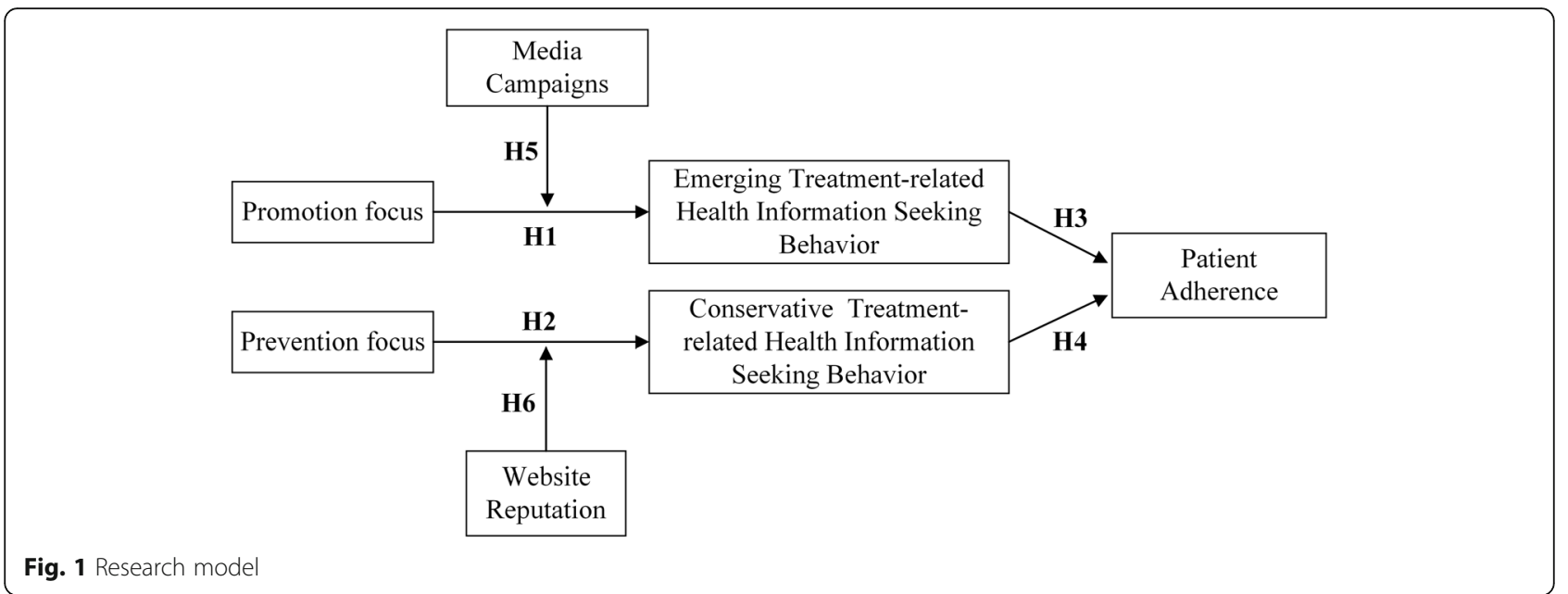

and prevention focus as independent variables, emerging treatment-related health information seeking behaviour and conservative treatment-related health information seeking behaviour as mediators, patient adherence as the dependent variable, and media campaigns and website reputation as moderators.

\section{Methods}

\section{Participants}

The participants in this study were Chinese individuals who had experiences seeking health information and going to hospitals within the previous month so that they could recall (1) their experiences in seeking health information related to their specific health conditions and (2) their experiences and feelings with regard to their treatments.

\section{Measurement instrument}

All variables in this research model (see Fig. 1) were measured by multiple-item scales widely used in previous studies to ensure significant reliabilities and validities. A 7-point Likert-type response format ranging from "strongly disagree" to "strongly agree" was used to measure all items. Additional file 1 provides a list of questionnaire items. Promotion focus and prevention focus were measured using two nine-item scales adopted from Lockwood et al. [36]. Emerging treatment-related and conservative treatment-related health information seeking behaviours were measured using a five-item scale adapted based on items from Lemire et al. [37]. In this study, patient adherence was measured using a five-item scale adapted by Laugesen et al. [2] based on items from Hausman [38]. As a moderator, media campaigns were used to evaluate the attitudes of individuals towards health information obtained through mass media, and they were measured using a 15 -item scale adopted from Lignowska et al. [39]. A four-item scale adopted from $\mathrm{Li}$ [40] was used to measure website reputation.

\section{Procedure}

Prior to the formal investigation, the questionnaire was translated from English into Chinese because our subjects were Chinese. First, we translated the scales into Chinese and modified some expressions for cross-cultural adaptation. Then, we invited 10 individuals from different fields of work with different ages, genders and educational levels to read the translated scales and provide recommendations to further modify them. This process ensured the readability and comprehensibility of the scales. Finally, the Chinese scales were translated back into English by an English-speaking professional to ensure consistency between the new English translation versions and the original versions.

An online questionnaire survey was conducted in June 2017. The questionnaire was completed anonymously. A statement on the front page of the questionnaire clarified the protection of the participants' privacy, and the participants' informed consent was secured. Each piece of equipment was allowed to fill in the questionnaire only once to avoid duplication. In the weeks preceding the survey, this questionnaire was pre-tested on 112 subjects to ensure that the scales were clear, concise, and easy to read and to determine the approximate time to complete the questionnaire. With the help of a medical association in China, we sent questionnaires to 486 participants and obtained 375 responses, 336 of which were valid. Therefore, the response rate was $77.16 \%$, and the valid response rate was $89.6 \%$. Table 1 shows the demographics of the valid responses.

A previous study indicated that a high proportion of individuals who are likely to search the Internet for health information are young and highly educated females [2]. In our study, the Internet was not the only 
Table 1 Demographics of the sample

\begin{tabular}{lll}
\hline & Number & Percentage \\
\hline (1) Age & 22 & \\
$<20$ & 83 & $6.55 \%$ \\
$21-29$ & 107 & $24.70 \%$ \\
$30-39$ & 59 & $31.84 \%$ \\
$40-49$ & 47 & $17.56 \%$ \\
$50-59$ & 18 & $13.99 \%$ \\
60 and above & & $5.36 \%$ \\
(2) Gender & 156 & \\
Male & 180 & $46.43 \%$ \\
Female & & $53.57 \%$ \\
(3) Resident status & 184 & \\
Urban & 152 & $54.76 \%$ \\
Rural & & $45.24 \%$ \\
(4) Education & 31 & \\
Junior middle school & 96 & $9.22 \%$ \\
High school & 68 & $28.57 \%$ \\
Junior college & 127 & $20.24 \%$ \\
Bachelor's degree & 9 & $37.80 \%$ \\
Master's degree & 5 & $2.68 \%$ \\
Doctoral degree & & \\
\hline
\end{tabular}

platform that could be used to seek health information; website reputation was also a moderator, and this survey was conducted through the Internet. Thus, the participants in this study met the requirements.

\section{Results}

Data analysis

This study drew lessons from some research methods in previous studies [3, 41]. Structural equation modelling (SEM) is a widely accepted paradigm [42] that can be used to test research models, including all variables, and to analyse the causal relations between model parameters [43]. Thus, it is suitable for use to analyse a research model containing mediators, moderators and complex relationships. Statistical analysis was performed using SPSS 22.0. The reliability of the measures was assessed by Cronbach's $\alpha$, which should be at least 0.70 [44]. Table 2 shows the Cronbach's $\alpha$ of each construct, which means acceptable reliability. The KMO (Kaiser-MeyerOlkin) value (weak: 0.50 ; medium: 0.60 ; good: 0.70 ; very good: 0.80; perfect: 0.90$)$ [45-48] was equal to 0.85 ( $p<$ 0.001 , significant) and above the cut-off value of 0.80 . Therefore, the data collected through our questionnaires were suitable for factor analysis.

We used confirmatory factor analysis (CFA) and SEM to analyse the data and to test the hypotheses. Based on the CFA results from SPSS AMOS 22.0, we deleted three
Table 2 Cronbach's a of the constructs

\begin{tabular}{ll}
\hline Construct $^{a}$ & Cronbach's a \\
\hline PROF & 0.80 \\
PREF & 0.76 \\
ETHISB & 0.84 \\
CTHISB & 0.86 \\
MC & 0.83 \\
WR & 0.91 \\
PA & 0.87 \\
Total & 0.85
\end{tabular}

${ }^{\mathrm{a} P R O F}$ promotion focus, PREF prevention focus, ETHISB emerging treatment-related health information seeking behaviour, CTHISB conservative treatment-related health information seeking behaviour, $M C$ media campaigns, WR website reputation, PA patient adherence

promotion focus items (PROF3, PROF4 and PROF6), four prevention focus items (PREF2, PREF4, PREF5 and PREF7) and two media campaign items (MC7 and MC15) with low loadings $(<0.50)$ or high cross-loadings $(>0.40)$. As shown in Table 3, the fit indices indicated a good fit and showed a consistency between the hypothesized model and the questionnaire data.

Table 4 provides the mean, standard deviation (SD), composite reliability (CR), and average variance extracted (AVE), and Table 5 presents the correlations between each of the two factors. The AVE and CR were used to evaluate convergent validity. For almost each measure, the AVE was above the cut-off value of 0.50 and the CR was above the cut-off value of 0.70 , indicating that the measures had an acceptable convergent validity. Discriminant validity was acceptable because the square root of the AVE of almost every construct exceeded the correlations between the other constructs in the model and itself (except for the correlation between promotion focus and prevention focus) $[53,54]$.

\section{Hypothesis testing}

First, we analysed the effects of demographic factors (age, gender, resident status, and educational level) on the research model using a t-test, analysis of variance (ANOVA) and analysis of covariance (ANOCOVA). We found that age, resident status, and educational level exerted significant effects on these relationships. Therefore, we added these variables into the research model as control variables. The results revealed that age exerted a

Table 3 Cronbach's a of the constructs

\begin{tabular}{lll}
\hline Fit indices & Values & $\begin{array}{l}\text { Threshold for a } \\
\text { good fit [49] }\end{array}$ \\
\hline $\begin{array}{l}\text { Root mean square error of } \\
\text { approximation (RMSEA) [50] }\end{array}$ & 0.03 & $<0.05$ \\
Goodness of fit index (GFI) [51] & 0.90 & $\geq 0.90$ \\
Comparative fit index (CFI) [52] & 0.96 & $\geq 0.90$ \\
\hline
\end{tabular}


Table 4 Composite reliability and average variance extracted

\begin{tabular}{llllll}
\hline Construct $^{\mathrm{a}}$ & Mean & SD & CR & AVE & Sqrt AVE \\
\hline PROF & 5.12 & 0.80 & 0.84 & 0.47 & 0.68 \\
PREF & 4.97 & 0.82 & 0.83 & 0.50 & 0.70 \\
ETHISB & 4.21 & 0.92 & 0.87 & 0.57 & 0.75 \\
CTHISB & 4.68 & 0.83 & 0.86 & 0.55 & 0.74 \\
MC & 3.63 & 0.69 & 0.91 & 0.53 & 0.73 \\
WR & 5.09 & 1.12 & 0.89 & 0.68 & 0.82 \\
PA & 5.25 & 0.85 & 0.88 & 0.60 & 0.78 \\
\hline
\end{tabular}

a PROF promotion focus, PREF prevention focus, ETHISB emerging treatment-related health information seeking behaviour, CTHISB conservative treatment-related health information seeking behaviour, $M C$ media campaigns, WR website reputation, $P A$ patient adherence

positive effect on conservative treatment-related health information seeking behaviour and that patients with different resident statuses held different attitudes towards seeking conservative treatment-related health information. Educational level did not have any effect on the variables of the research model. Figure 2 and Table 6 show the magnitude and significance of the path coefficients. It is found that five hypotheses $(\mathbf{H 1}, \mathbf{H} 2, \mathbf{H 4}, \mathbf{H 5}$, and H6) were supported. The impact directions of all supported hypotheses were consistent with the path coefficients. H3 was not supported, and the path coefficient between emerging treatment-related health information seeking behaviour and patient adherence was not significant because it was near zero. To further test the mediating effects, we used the bootstrapping method ( $n=1000,95 \% \mathrm{CI}$ ) with SPSS AMOS 22.0. We found that conservative treatment-related health information seeking behaviour played a total mediating role between prevention focus and patient adherence [55].

\section{Discussion}

\section{Principal results}

This study identified how regulatory focus influences patient adherence through the mediation of health information seeking behaviour and considered the moderating effects of media campaigns and website reputation on this

Table 5 Correlations between two constructs

\begin{tabular}{llllllll}
\hline Construct $^{a}$ & PROF & PREF & ETHISB & CTHISB & MC & WR & PA \\
\hline PROF & 1.00 & & & & & & \\
PREF & 0.85 & 1.00 & & & & & \\
ETHISB & 0.41 & 0.29 & 1.00 & & & & \\
CTHISB & 0.31 & 0.41 & 0.30 & 1.00 & & & \\
MC & 0.03 & 0.13 & 0.22 & 0.17 & 1.00 & & \\
WR & 0.35 & 0.32 & 0.31 & 0.34 & -0.18 & 1.00 & \\
PA & 0.33 & 0.25 & 0.15 & 0.34 & -0.23 & 0.38 & 1.00 \\
\hline PROF prom
\end{tabular}

${ }^{a} P R O F$ promotion focus, PREF prevention focus, ETHISB emerging treatment-related health information seeking behaviour, CTHISB conservative treatment-related health information seeking behaviour, $M C$ media campaigns, WR website reputation $P A$ patient adherence relationship. The hypothesis testing results indicate that we can substantially ascertain (1) the relationship between regulatory focus and health information seeking behaviour, (2) the relationship between the conservative treatment-related health information seeking behaviour of patients with a prevention focus and patient adherence, and (3) the moderating effects of media campaigns and website reputation on the relationship between regulatory focus and health information seeking behaviour.

The development of the Internet allows people to freely post and review health-related topics online. Consistent with our hypothesis, regulatory focus strongly affects health information seeking behaviour. Specifically, individuals with a promotion focus are more likely to seek emerging treatment-related health information, whereas individuals with a prevention focus prefer conservative treatment-related health information because incautious people accept more risk while conservative people accept less risk [30]. Therefore, a system that recommends Internet health information for users according to their regulatory focus and risk preference may be designed. For example, users can answer some questions so that their regulatory focus and risk preference can be preliminarily judged. On the basis of their regulatory focus and some keywords input by users, such a system can provide appropriate health information for users based on some algorithms. Our findings also show the differences in health information seeking behaviours among different age groups. Thus, age may be an important factor that should be included in such a system.

Conservative treatment-related health information seeking behaviour is an important factor affecting patient adherence. Contradicting our hypothesis, the emerging treatment-related health information seeking behaviour of patients with a promotion focus did not have any significant effect on patient adherence. Additional analyses were performed to explore why $\mathbf{H} \mathbf{3}$ was not supported. Considering that other factors may inhibit this relationship, we intended to analyse the direct effect of emerging treatment-related health information seeking behaviour on patient adherence without considering their other effects on patient adherence. The path from conservative treatment-related health information seeking behaviour to patient adherence was disregarded. Consequently, emerging treatment-related health information seeking behaviour significantly affected patient adherence. However, the impact was positive, but not negative as $\mathbf{H} 3$ hypothesized. This finding may be attributed to the lack of accurate definitions for emerging treatment-related health information and conservative treatment-related health information in the questionnaire, which resulted in possible confusion between these two types of health information. In other words, conservative treatment-related health information may 


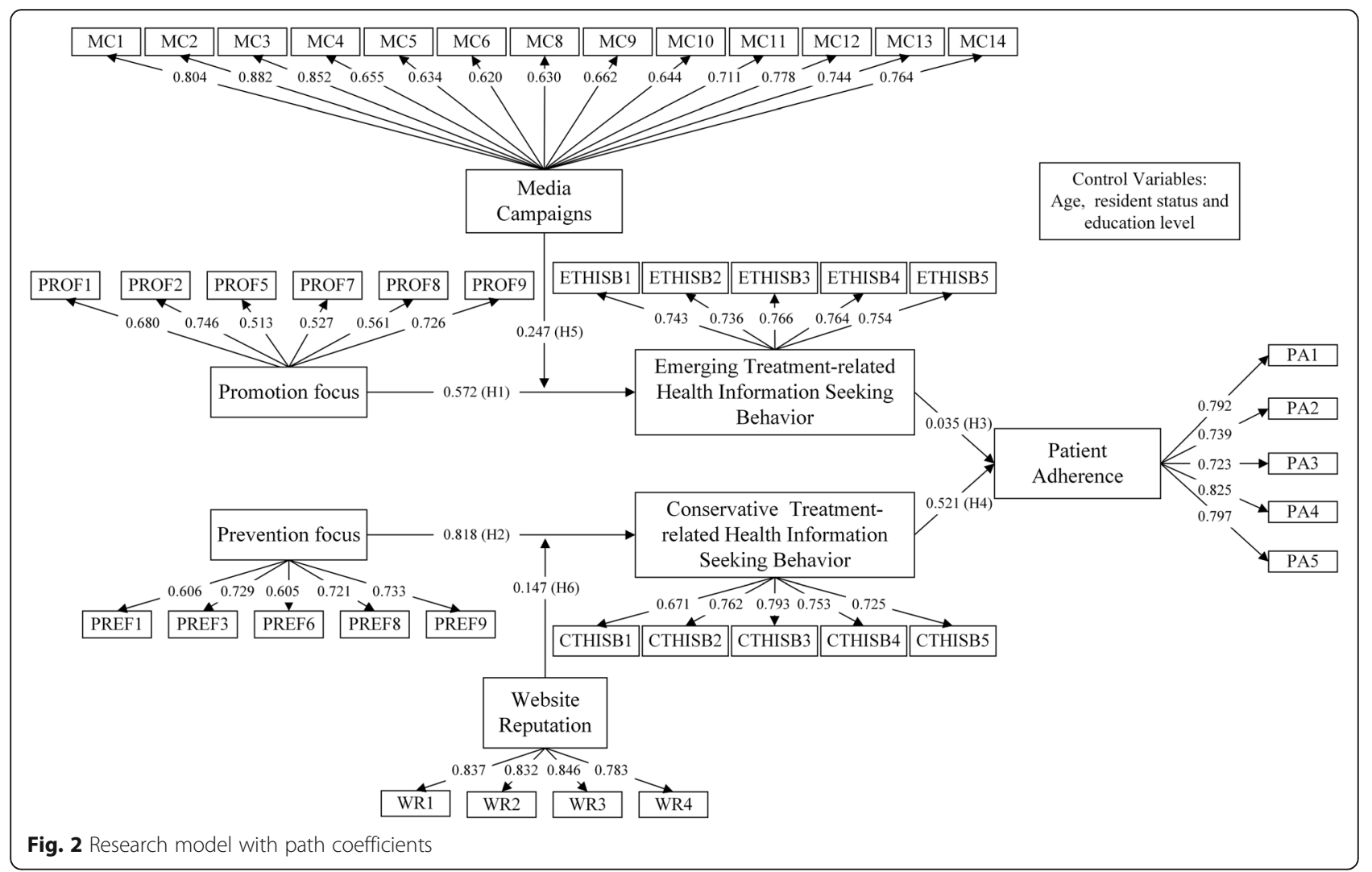

also be emerging, and vice versa, which possibly resulted in confusion. Considering this reason, we have not clarified the specific relationship between emerging treatmentrelated health information seeking behaviour and patient adherence. Nevertheless, we still believe that emerging treatment-related health information may affect patient adherence. For example, when a physician advises a patient to use a new technology, individuals with a prevention focus may be hesitant to follow the physician's advice [30], whereas individuals with a promotion focus may be interested in the new technology. Therefore, patients will tend to seek further information about it and change their adherence.

Despite the confusion between conservative treatmentrelated and emerging treatment-related health information during the survey, we can ensure that conservative treatment-related health information seeking behaviour has a positive effect on patient adherence. In other words, conservative treatment-related health information is a preferred type of health information. Thus, we should pay more attention to this type of health information. On the one hand, in terms of the quality of conservative

Table 6 Results of hypothesis testing

\begin{tabular}{|c|c|c|}
\hline Hypotheses & Path coefficient & $P$ \\
\hline $\begin{array}{l}\text { Promotion focus has a positive impact on patients' emerging treatment-related health } \\
\text { information seeking behaviour. }\end{array}$ & 0.527 & $<0.001$ \\
\hline $\begin{array}{l}\text { Prevention focus has a positive impact on the patients' conservative treatment-related } \\
\text { health information seeking behaviour. }\end{array}$ & 0.818 & $<0.001$ \\
\hline $\begin{array}{l}\text { The emerging treatment-related health information seeking behaviour of patients } \\
\text { with a promotion focus has a negative impact on their adherence. }\end{array}$ & 0.035 & 0.593 \\
\hline $\begin{array}{l}\text { The conservative treatment-related health information seeking behaviour of patients } \\
\text { with a prevention focus has a positive impact on their adherence. }\end{array}$ & 0.521 & $<0.001$ \\
\hline $\begin{array}{l}\text { If the level of media campaigns increases, then the relationship between promotion } \\
\text { focus and emerging treatment-related health information seeking behaviour will be } \\
\text { strengthened. }\end{array}$ & 0.247 & $<0.001$ \\
\hline $\begin{array}{l}\text { If the level of website reputation increases, then the relationship between prevention } \\
\text { focus and conservative treatment-related health information seeking behaviour will be } \\
\text { strengthened. }\end{array}$ & 0.147 & 0.011 \\
\hline
\end{tabular}


treatment-related health information, we should strengthen its supervision and take measures to improve it. Physicians, professionals, and investigators can be invited to review the quality of conservative treatment-related health information. On the other hand, physicians should be required to improve their professionalism [2] and expand their knowledge of conservative healthcare to widen the gap between the conservative treatment-related health information obtained by patients from the Internet and that acquired from physicians, thereby increasing patients' perceived information asymmetry and thus improving patient adherence.

Additionally, we identified the significant moderating effects of (1) media campaigns on the relationship between promotion focus and emerging treatment-related health information seeking behaviour and (2) website reputation on the relationship between prevention focus and conservative treatment-related health information seeking behaviour. These results are consistent with our assumptions. The additional analyses indicate the direct effects of (1) media campaigns on emerging treatmentrelated health information seeking behaviour and (2) website reputation on conservative treatment-related health information seeking behaviour, which we did not hypothesize. The number of health information portals established by governments, medical institutions, and business corporations has significantly increased [56]. Moreover, obtaining information through mass media such as the Internet has become a lifestyle. Thus, individuals can be encouraged to seek health information and share health-related knowledge on the Internet as long as the quality of information is guaranteed.

\section{Limitations}

The limitations of this study must be considered. First, we focused on patient adherence, which is only one aspect of the physician-patient relationship. Other factors concerning this relationship may also warrant investigation. Second, we did not identify the differences between the independent variables and the moderators. Specifically, media campaigns and website reputation were moderators in our research model, but they could also be considered independent variables in further analyses. Third, all concepts and relationships were measured only once. Thus, this study was conducted from a static perspective, which may be why the convergent validity of the correlation between promotion focus and prevention focus was unacceptable, even though we adopted the scale from previous valid works. Therefore, future studies can conduct the survey more than once. Fourth, all conclusions in this study are based on relationships between questionnaire responses in the absence of external validation. Finally, this study simplified a complex issue with many dimensions. For example, we abstracted the research background of patient adherence. Future studies can address the specific disease to accurately identify the impact of regulatory focus on patient adherence.

\section{Conclusion}

Our findings suggest that conservative treatment-related health information is the most important element in our research model and that regulatory focus influences patient adherence through health information seeking behaviour. Specifically, regulatory focus has two aspects: promotion focus and prevention focus. Individuals with a promotion focus tend to seek emerging treatment-related health information, whereas individuals with a prevention focus tend to seek conservative treatmentrelated health information. The above findings suggest that conservative treatment-related health information may dominate the impact on patient adherence and that conservative treatment-related health information seeking behaviour is always influenced by prevention focus. Aside from the moderating effects, media campaigns and website reputation also directly affect health information seeking behaviour. Individuals are encouraged to seek health information and share health-related knowledge through mass media such as the Internet when the quality of information, especially information from online sources, is guaranteed. Moreover, traditional mass media and online sources should improve the quality of information to attract individuals to seek health information. Conservative treatment-related health information may be the most noteworthy.

\section{Additional file}

Additional file 1: Table S1. Measurement Instrument. (DOCX 19 kb)

\section{Abbreviations}

AVE: Average variance extracted; CFA: Confirmatory factor analysis; CFI: Comparative fit index; CR: Composite reliability; CTHISB: Conservative Treatment-related Health Information Seeking Behaviour; ETHISB: Emerging Treatment-related Health Information Seeking Behaviour; KMO: Kaiser-MeyerOlkin; MC: Media Campaigns; NFI: Normed fit index; PA: Patient Adherence; PREF: Prevention focus; PROF: Promotion focus; RMSEA: Root mean square error of approximation; SD: Standard deviation; SEM: Structural equation modeling; SPSS: Statistic Package for Social Science; WR: Website Reputation

\section{Acknowledgements}

Not applicable

\section{Funding}

This study design, data collection, analysis, data interpretation, and writing were supported by the National Natural Science Foundation of China (grant number 71532002), the National Social Science Foundation of China (grant number 18ZDA086), and the Fundamental Research Funds for the Central Universities (grant number 2019YJS056). The content is solely the responsibility of the authors and does not necessarily represent the official views of these funding organizations. The funding bodies had no role in the design of the study and collection, analysis, and interpretation of data and in writing the manuscript. 


\section{Availability of data and materials}

The datasets used and/or analyzed during the current study are available from the corresponding author on reasonable request.

\section{Authors' contributions}

All four authors contributed to this study. RTZ conceived and design the study, developed the research model. XYL participated in designing the study and developing the research model, designed the questionnaire, conducted data collection and analysis, and is a major contributor in writing and revising the manuscript. WW and XPS helped analyze data, test hypotheses and draft as well as modify the manuscript. All authors read and approved the final manuscript.

\section{Ethics approval and consent to participate}

Ethics approval (case reference number: BJ201704007) was obtained from the Ethics Committee of School of Economics and Management, Beijing Jiaotong University in China in which the study was undertaken. The informed consent was obtained in written form.

\section{Consent for publication}

Not applicable

\section{Competing interests}

The authors declare that they have no competing interests.

\section{Publisher's Note}

Springer Nature remains neutral with regard to jurisdictional claims in published maps and institutional affiliations.

\section{Received: 14 May 2018 Accepted: 25 April 2019}

\section{Published online: 10 May 2019}

\section{References}

1. Greenfield G, Pliskin JS, Feder-Bubis P, Wientroub S, Davidovitch N. Patientphysician relationships in second opinion encounters-the physicians' perspective. Soc Sci Med. 2012;75(7):1202-12.

2. Laugesen J, Hassanein K, Yuan YF. The impact of internet health information on patient compliance: a research model and an empirical study. J Med Internet Res. 2015;17(6):e143.

3. Whittal A, Lippke S. Investigating patients with an immigration background in Canada: relationships between individual immigrant attitudes, the doctorpatient relationship, and health outcomes. BMC Public Health. 2015;16(1):23.

4. Haynes RB, Taylor DW, Sackett DL. Compliance in Health Care. Baltimore, Md: Johns Hopkins University Press; 1979.

5. Osterberg L, Blaschke T. Adherence to medication. New Engl J Med. 2005; 353(18):1972-4

6. Marck CH, De LAM, Brown CR, Neate SL, Taylor KL, Weiland TJ, et al. Health outcomes and adherence to a healthy lifestyle after a multimodal intervention in people with multiple sclerosis: three-year follow-up. PLoS One. 2018;13(5):e0197759.

7. Müller AM, Osório CS, Silva DR, Sbruzzi G, de Tarso P, Dalcin R. Interventions to improve adherence to tuberculosis treatment: systematic review and meta-analysis. Int. J. Tuberc. Lung Dis. 2018;22(7):731-40.

8. Silva BM, Rodrigues JJ, de la Torre Díez I, López-Coronado M, Saleem K. Mobile-health: a review of current state in 2015. J Biomed Inform. 2015;56: 265-72.

9. Peng R, Wu B. Changes of health status and institutionalization among older adults in China. Journal of Aging and Health. 2015;27(7):1223-46.

10. Cen L, Emma C, Livingston PM, Botti M. Perceptions of patient participation in symptom management: a qualitative study with cancer patients, doctors and nurses. J Adv Nurs. 2019;75(2):412-22.

11. Barbouni A, Nalmpanti M, Gennimata D, Theodoridis D, Merakou K. Beliefs and practices of Greek doctors in relation to patients' adherence to antihypertensive medication. J Hum Hypertens. 2017;31(5):341-6.

12. Ross $S$, Walker A, Macleod MJ. Patient compliance in hypertension: role of illness perceptions and treatment beliefs. J Hum Hypertens. 2004;18(9):607-13.

13. Raju S, Hollis K, Neglen P. Use of compression stockings in chronic venous disease: patient compliance and efficacy. Ann Vasc Surg. 2007;21(6):790-5.

14. Fe Y, Li XJ, Jiang WL, Sun HB, Liu J. Efficacy of and patient compliance with a ketogenic diet in adults with intractable epilepsy: a meta-analysis. J Clin Neurol. 2015;11(1):26-31.
15. Maningat $P$, Gordon BR, Breslow JL. How do we improve patient compliance and adherence to long-term statin therapy. Curr Atheroscler Rep. 2013;15(1): 291.

16. Philippot P, Lenoir N, D'Hoore W, Bercy P. Improving patients' compliance with the treatment of periodontitis: a controlled study of behavioural intervention. J Clin Periodontol. 2005;32(6):653-8.

17. Perrell-Jones C, Ireland RS. What factors influence patient compliance with supportive periodontal therapy in a general practice setting. Brit Dent J. 2016;221(11):701-4.

18. Köberlein J, Kothe AC, Schaffert C. Determinants of patient compliance in allergic rhino conjunctivitis. Curr Opin in Allergy Cl. 2011;11(3):192-9.

19. Marques PAC, Pierin AMG. Factors that affect cancer patient compliance to oral anti-neoplastic therapy. Acta Paul Enferm. 2008;21(2):323-9.

20. Tsai JC. Medication adherence in glaucoma: approaches for optimizing patient compliance. Curr Opin Ophthalmol. 2006;17(2):190-5.

21. Bondesson A, Hellström L, Eriksson T, Höglund P. A structured questionnaire to assess patient compliance and beliefs about medicines taking into account the ordered categorical structure of data. J Eval Clin Pract. 2009;15(4):713-23

22. Crowe E, Higgins ET. Regulatory focus and strategic inclinations: promotion and prevention in decision-making. Organ Behav Hum Dec. 1997;69(2):117-32.

23. Higgins ET. Self-discrepancy: a theory relating self and affect. Psychol Rev. 1987;94(3):319-40

24. Higgins ET. Beyond pleasure and pain. Am Psychol. 1997;52(12):1280-300.

25. Anderson JG, Rainey MR, Eysenbach G. The impact of cyber healthcare on the physician-patient relationship. J Med Syst. 2003;27(1):67-84.

26. Mota LRAD, Ferreira CCG, Neto C, Falbo AR, Lorena SDB. Is doctor-patient relationship influenced by health online information. Revista da Associação Médica Brasileira. 2018;64(8):692-9.

27. Marcinkiewicz M, Mahboobi $\mathrm{H}$. The impact of the internet on the doctorpatient relationship. Australas Med J. 2009;1(5):102-4.

28. Wilson TD. Human information behavior. Inform Science. 2000;3(2):49-56.

29. Kaziunas E, Hanauer DA, Ackerman MS, Choi SW. Identifying unmet informational needs in the inpatient setting to increase patient and caregiver engagement in the context of pediatric hematopoietic stem cell transplantation. J Am Med Inform Assn. 2015;23(1):94-104.

30. Liu J, Modrek S, Anyanti J, Nwokolo E, Cruz ADL, Schatzkin E, Isiguzo C, Ujuju C, Montagu D. How do risk preferences relate to malaria care-seeking behavior and the acceptability of a new health technology in Nigeria. BMC Health Serv Res. 2014;14(1):374.

31. Jesus MD. The impact of mass media health communication on health decision-making and medical advice-seeking behavior of US Hispanic population. Health Commun. 2012;28(5):525-9.

32. Kim J, Jung M. Associations between media use and health informationseeking behavior on vaccinations in South Korea. BMC Public Health. 2017; 17(1):700.

33. Pjesivac I, Rui R. Anonymous sources hurt credibility of news stories across cultures: a comparative experiment in America and China. Int Commun Gaz. 2014;76(8):641-60

34. Im H, Huh J. Does health information in mass media help or hurt patients? Investigation of potential negative influence of mass media health information on patients' beliefs and medication regimen adherence. J Health Commun. 2017;22(3):1-9.

35. Akroush MN, Al-Debei MM. An integrated model of factors affecting consumer attitudes towards online shopping. Bus Process Manag J. 2015;21(6):1353-76.

36. Lockwood P, Jordan CH, Kunda Z. Motivation by positive or negative role models: regulatory focus determines who will best inspire us. J Pers Soc Psychol. 2002;83(4):854-64.

37. Lemire M, ParéG SC, Harvey C. Determinants of internet use as a preferred source of information on personal health. Int J Med Inform. 2008;77(11): 723-34.

38. Hausman A. Modeling the patient-physician service encounter: improving patient outcomes. J Acad Market Sci. 2004;32(4):403-17.

39. Lignowska I, Borowiec A, Slonska Z. The relationship between audience mentality and attitudes towards healthy lifestyle promotion in the mass media. Glob Health Promot. 2016;23(3):36-44.

40. Li Y. The impact of disposition to privacy, website reputation and website familiarity on information privacy concerns. Decis Support Syst. 2013;57(1):343-54.

41. Wiertz C, Ruyter KD. Beyond the call of duty: why customers contribute to firm-hosted commercial online communities. Organ Stud. 2007;28(3):347-76. 
42. Hoque R, Sorwar G. Understanding factors influencing the adoption of mHealth by the elderly: an extension of the UTAUT model. Int J Med Inform. 2017;101:75-84.

43. Yu P, Li HC, Gagnon MP. Health IT acceptance factors in long-term care facilities: a cross-sectional survey. Int J Med Inform. 2009;78(4):219-29.

44. Mollayeva T, Thurairajah P, Burton K, Mollayeva S, Shapiro CM, Colantonio A The Pittsburgh sleep quality index as a screening tool for sleep dysfunction in clinical and non-clinical samples: a systematic review and meta-analysis. Sleep Med Rev. 2015;25:52-73.

45. Kaiser HF. A second generation little jiffy. Psychometrika. 1970;35(4):401-15.

46. Kurtuldu MK, Bulut D. Development of a self-efficacy scale toward piano lessons. Kuram Uygulama Egi. 2017;17(3):835-57.

47. Biasutti M, Frate S. A validity and reliability study of the attitudes toward sustainable development scale. Environ Educ Res. 2017;23(2):214-30.

48. Erdogan M, Ok A, Marcinkowski TJ. Development and validation of children's responsible environmental behavior scale. Environ Educ Res. 2012;18(4):507-40

49. Nuñosolinís R, Berraondo ZI, Sauto AR, San MRL, Toro PN. Development of a questionnaire to assess interprofessional collaboration between two different care levels. Int J Integr Care. 2013;13(2):e015.

50. Steiger JH. Statistically based tests for the number of common factors. Paper presented at the annual meeting of the psychometric society, lowa City, 1980

51. Mcdonald RP. An index of goodness-of-fit based on noncentrality. J Classif. 1989;6(1):97-103.

52. Bentler PM, Kano $Y$. On the equivalence of factors and components. Multivariate Behav Res. 1990;25(1):67-74

53. Fornell C, Larcker DF. Evaluating structural equation models with unobservable variables and measurement error. J Marketing Res. 1981; 18(1):39-50.

54. Sobral MP, Costa ME, Schmidt L, Martins MV. Corrigendum: COMPI fertility problem stress scales is a brief, valid and reliable tool for assessing stress in patients seeking treatment. Hum Reprod. 2017;32(2):375.

55. Zheng J, Wu G. Work-family conflict, perceived organizational support and professional commitment: a mediation mechanism for Chinese project professionals. Int J Environ Res Public Health. 2018;15(2):344.

56. Li F, Li M, Guan P, Ma S, Cui L. Mapping publication trends and identifying hot spots of research on internet health information seeking behavior: a quantitative and co-word biclustering analysis. J Med Internet Res. 2015; 17(3):e81.

Ready to submit your research? Choose BMC and benefit from:

- fast, convenient online submission

- thorough peer review by experienced researchers in your field

- rapid publication on acceptance

- support for research data, including large and complex data types

- gold Open Access which fosters wider collaboration and increased citations

- maximum visibility for your research: over $100 \mathrm{M}$ website views per year

At $\mathrm{BMC}$, research is always in progress.

Learn more biomedcentral.com/submissions 